\title{
EXTENSION OF WEIBULL MODEL FOR DESCRIBING OF DRIED APPLE REHYDRATION
}

Krzysztof GÓRNICKI, Department of Fundamental Engineering, Faculty of Production Engineering, Warsaw University of Life Sciences, 02-787 Warszawa, Nowoursynowska 164, Poland, krzysztof_gornicki@sggw.pl (corresponding author)

Agnieszka KALETA, Department of Fundamental Engineering, Faculty of Production Engineering, Warsaw University of Life Sciences, 02-787 Warszawa, Nowoursynowska 164, Poland, agnieszka kaleta@sggw.pl

Aneta CHOIŃSKA, Department of Fundamental Engineering, Faculty of Production Engineering, Warsaw University of Life Sciences, 02-787 Warszawa, Nowoursynowska 164, Poland, aneta_choinska@sggw.pl

Sample of Ligol variety apples (slices of 3 and $10 \mathrm{~mm}$ thickness and cubes of $10 \mathrm{~mm}$ thickness) were dried using following methods: natural convection (drying air velocity amounted to $0.01 \mathrm{~m} / \mathrm{s}$ ), forced convection $(0.5$ and $2 \mathrm{~m} / \mathrm{s})$, fluidized bed drying $(6 \mathrm{~m} / \mathrm{s})$. The drying air temperature was kept at 50,60 , and $70^{\circ} \mathrm{C}$. The dried apples samples were rehydrated in distilled water at $20,45,70$, and $95^{\circ} \mathrm{C}$. The Weibull model given for describing time dependence of the moisture content change was fitted to experimental data and model parameters were determined by multiple regression analysis. The variation of model parameters with characteristic particle dimension $(L)$, drying air velocity $(v)$, drying air temperature $\left(t_{d}\right)$, and rehydration temperature $\left(t_{r}\right)$ described as multiplication type. By using these verification of parameters, extended Weibull model for describing combine effects of $L, v, t_{d}$, $t_{r}$, and drying time was derived and the parameters of the model were also determined by multiple regression analysis. The accuracies of both models were measured using the determination coefficient $\left(\mathrm{R}^{2}\right)$, mean bias error (MBE), root mean square error (RMSE), reduced chi-square $\left(\chi^{2}\right)$, and t-statistic method. The Weibull model $\left(\mathrm{R}^{2}=0.8319-0.9957, \mathrm{MBE}=-0.0044-0.0110, \mathrm{RMSE}=0.0189-0.1248, \chi^{2}=0.0004-0.0180\right.$, and $\mathrm{t}$-stat=0.0149-0.2875) and the extended Weibull model $\left(\mathrm{R}^{2}=0.9130-0.9948, \mathrm{MBE}=-0.0209-0.0377, \mathrm{RMSE}=0.0230-0.0719, \chi^{2}=0.0007-\right.$ 0.0057 , and t-stat $=0.0389-1.2214$ ) described the rehydration characteristics of dried apple satisfactorily. The extended model by taking into account the effect of $L, v, t_{d}$, and $t_{r}$ on its parameters can be considered as more general one.

Keywords: apple, rehydration, Weibull model.

\section{INTRODUCTION}

The knowledge of the rehydration kinetics of dried products is important to optimise process from a quality point of view because rehydration is a key quality aspect for those dried products that have to be reconstituted before their consumption. Different transport mechanisms take place during rehydration of dried food products, namely molecular diffusion, convection, hydraulic flow, and capillary flow (Saguy et al. 2005). The mathematical modelling of the rehydration process is the most important aspect of rehydration technology. Different authors modelled discussed process. Some of them proposed theoretical models among others such based on Fick's law of diffusion. Górnicki (2011) used theoretical model to describing of dried apple and parsley root rehydration. Maldonado et al. (2010) and Markowski et al. (2009) used mentioned model for describing of dried mangoes and potato rehydration, respectively.

Empirical models such as the Peleg (1988) model, Weibull model (Garcia-Pascual et al. 2006) or Witrowa-Rajchert (1999) model are not derived from any physical laws but their application is relatively easy.

The Weibull model has been found to give satisfactory results in the description of rehydration of the dried materials. Ergün et al. (2016) determined the rehydration kinetics of freeze dried (13.33 $\mathrm{Pa}$ absolute pressure, $-48^{\circ} \mathrm{C}$ condenser temperature) kiwi slices. Rehydration experiments were carried out in distilled water at a temperature of $18^{\circ} \mathrm{C}$. The solid: liquid ratios were adjusted as 1:25, 1:50, 1:75, 1:100, and 1:125 (w:w). The kinetics of the moisture absorption of the kiwi slices was modelled by the application Weibull model. The results showed that the Weibull model was not well fitted to the experimental data due to low $\mathrm{R}^{2}$ values $(0.677-0.9232)$. Link et al. (2017) compared different drying methods (conductive multi-flash drying, air-drying, vacuum drying, and freeze-drying) with respect to rehydration kinetics of dried mangoes slices. Dried mangoes were immersed in distilled water (1:100 - dried mango weight: water weight) at $20^{\circ} \mathrm{C}$ and $80^{\circ} \mathrm{C}$. The Exponential model, Peleg model and Weibull model were used for describing the rehydration of mango samples. However, the best statistical parameters were obtained fitting the Weibull model to the experimental data, thus this model was considered the most accurate for describing the rehydration kinetics of dried mangoes. Garcia-Pascual et al. (2005) examined of rehydration of air-dried Morchella esculenta mushrooms at 15, 20, $25,30,45,55$ and $70^{\circ} \mathrm{C}$. Authors used Weibull model to describe the kinetics of rehydration. Rafiq et al. (2015) examined

Copyright (C) 2017 The Authors. Published by Aleksandras Stulginskis University. This is an open-access article distributed under the terms of the Creative Commons Attribution License (CC-BY 4.0), which permits unrestricted use, distribution, and reproduction in any medium, provided the original author and source are credited. 
hydration behaviour with processing conditions of low amylose content parboiled rice which was dried at 40,50 and $60^{\circ} \mathrm{C}$. The rehydration characteristics of the parboiled rice was studied at various soaking temperatures $\left(30,40\right.$ and $\left.50^{\circ} \mathrm{C}\right)$. Three semi-empirical models: Peleg model, Exponential model, and Weibull model were examined for fitting the experimental data of water uptake kinetics of parboiled paddy. The average $\mathrm{R}^{2}$ value of fit was 0.963 for Peleg's equation and 0.973 for Exponential and 0.986 for Weibull equation. Machado et al. (1999) measured the moisture uptake by readyto-eat corn breakfast cereal immersed in milk solutions, reconstituted from whole and skimmed milk powder under isothermal conditions at 5,30 and $55^{\circ} \mathrm{C}$. The Weibull model described the moisture uptake process by corn breakfast cereal adequately.

The objectives of this study were: (1) to apply the Weibull model to the description of moisture content changes during rehydration of dried apples, (2) to determine the effect of characteristic particle dimension, drying air velocity, drying air temperature, and rehydration temperature on model parameters. It turned out from the literature survey that there is no information on the subject undertaken in this study.

\section{MATERIAL AND METHODS}

High-quality Ligol apples bought at a Warsaw market were used in the research. The raw material was washed, peeled, and cut into slices of 3 and $10 \mathrm{~mm}$ thickness and cubes of $10 \mathrm{~mm}$ thickness. The apple samples were dried using following methods: natural convection (drying air velocity amounted to $0.01 \mathrm{~m} / \mathrm{s}$ ), forced convection $(0.5 \mathrm{and} 2 \mathrm{~m} / \mathrm{s})$, and fluidized bed drying $(6 \mathrm{~m} / \mathrm{s})$. The drying air temperature was kept at 50,60 , and $70^{\circ} \mathrm{C}$. The drying lasted until the constant weight of the dried material was attained. Dried material obtained in the same conditions was stored in air-tight glass container until it was used in the rehydration experiments.

The dried apples samples were rehydrated in distilled water at 20,45, 70, and $95^{\circ} \mathrm{C}$. Rehydration lasted from $6 \mathrm{~h}$ $\left(\right.$ at $20^{\circ} \mathrm{C}$ ) to $2 \mathrm{~h}\left(\right.$ at $95^{\circ} \mathrm{C}$ ). The initial mass of the dried material subjected to rehydration amounted to ca. $10 \mathrm{~g}$.

Mass determination process was conducted as follows: samples were weighted at least 7 times during the rehydration. Rehydrated samples were separated from the distilled water, dried with the blotting and weighted. The samples were next used to measure dry matter of solid content. Dry matter of solid was determined according to AOAC (2003) standards and was determined 7 times during the rehydration. The mass and dry matter measurements were replicated three times. The WPE 300 scales (RADWAG, Radom) were used for the measurements. The maximum relative error in the determination of the mass and dry matter mass amounted to $0.1 \%$.

The moisture content (dry basis) $M$ was calculated from formula

$$
M(\tau)=\frac{m(\tau)-m_{\mathrm{d} . \mathrm{m} .}}{m_{\mathrm{d} . \mathrm{m} .}}
$$

where: $m(\tau)$ is the mass $(\mathrm{g}), \tau$ is the time $(\mathrm{s}), m_{\mathrm{d} . \mathrm{m} .}$ is the mass of dry matter $(\mathrm{g})$.

The moisture ratio was calculated from formula

$$
\operatorname{MR}(\tau)=\frac{M(\tau)-M_{0}}{M_{e}-M_{0}}
$$

where: $M_{0}$ is the initial moisture content (dry basis), $M_{e}$ is the moisture content at saturation (equilibrium moisture content, dry basis).

The Weibull model was used to describe the rehydration kinetics

$$
\operatorname{MR}(\tau)=1-\exp \left[-\left(\frac{\tau}{\alpha}\right)^{\beta}\right]
$$

where: $\alpha$ is the scale parameter (s), $\beta$ is the dimensionless shape parameter.

The goodness of fit of the model to the experimental data was evaluated with the determination coefficient $\left(\mathrm{R}^{2}\right)$, mean bias error (MBE), root mean square error (RMSE), reduced chi-square $\left(\chi^{2}\right)$, and $t$-statistic method. The higher the $\mathrm{R}^{2}$ value and lower the values of MBE, RMSE, $\chi^{2}$, and $\mathrm{t}$-stat, the better the goodness of the fit.

The effect of characteristic particle dimension $L(\mathrm{~mm})$, drying air velocity $v(\mathrm{~m} / \mathrm{s})$, drying air temperature $t_{d}\left({ }^{\circ} \mathrm{C}\right)$, and rehydration temperature $t_{r}\left({ }^{\circ} \mathrm{C}\right)$ on parameters $\alpha$ and $\beta$ was also investigated by multiple regression analysis. The parameters were determined by investigating the four-variable polynomial function. The regression analyses and ANOVA $(\mathrm{p}<0.05)$ were done using the STATISTICA routine.

\section{RESULTS AND DISCUSSION}

Plot for variation in mass, dry matter of solid, and moisture content with time during rehydration are shown in Figure 1. It can be seen from Figure 1a and Figure 1c that moisture uptake increases with increasing rehydration time, and the rate is faster in initial period of rehydration and decreased up to the saturation level. This initial period of high water uptake can be attributed to the capillaries and cavities near the surface filling up rapidly (Cunningham et al. 2008). It can be observed from Figure $1 \mathrm{~b}$ that solute loss increases with increasing rehydration time, and the rate is faster in the initial period of rehydration and decreased up to the saturation level. The explanation of such a course of variation in dry matter of solid with time can be the 
following. There is an initial steep decrease in solid content because of a high rate of mass transfer. As the solute concentration equilibrated with the environment, the rate of change of solid dry matter is substantially reduced (Sopade et al., 2007).

The results of statistical analyses undertaken on the Weibull model are given in Table 1. As can be seen from the statistical analysis results, generally high determination coefficient $\mathrm{R}^{2}(0.8319-0.9957)$ and low values of MBE (-0.00440.0108), RMSE (0.0189-0.1248), $\chi^{2}$ (0.0004-0.0180), and t-stat (0.0149-0.2875) were found for Weibull model. Therefore, it can be accepted that considered model may be assumed to represent the rehydration behaviour of dried apples.

Further regressions were undertaken to account for the effect of $L, v, t_{d}$, and $t_{r}$ on the Weibull model parameters $\alpha$ and $\beta$. It turned out from the ANOVA $(\mathrm{p}<0.05)$ that polynomial function takes the following form (empirical formulas)

$$
\begin{gathered}
\alpha=4.454204-0.160544 L^{2}-0.003603 t_{d} t_{r}+0.001113 L t_{d} t_{r} \\
\beta=0.591161-0.000117 t_{r}^{2}+0.000209 t_{d} t_{r} v+0.000068 L t_{d} t_{r}-0.004333 L t_{r} v
\end{gathered}
$$

where: $L$ in $\mathrm{mm}, v$ in $\mathrm{m} / \mathrm{s}, t_{d}$ in ${ }^{\circ} \mathrm{C}, t_{r}$ in ${ }^{\circ} \mathrm{C}$, and $L$ depends not only on the particle dimension but the particle shape as well and according to Pabis et al. (1998): $L=s$ for slice of thickness $2 s$ and $L^{-2}=3 s^{-2}$ for cube thickness $2 s$.

As can be seen the values of scale parameter $\alpha$ and shape parameter $\beta$ depend on characteristic particle dimension, drying air temperature, and rehydration temperature. The values of $\beta$ depend moreover on drying air velocity (Eq. (5)).

a)

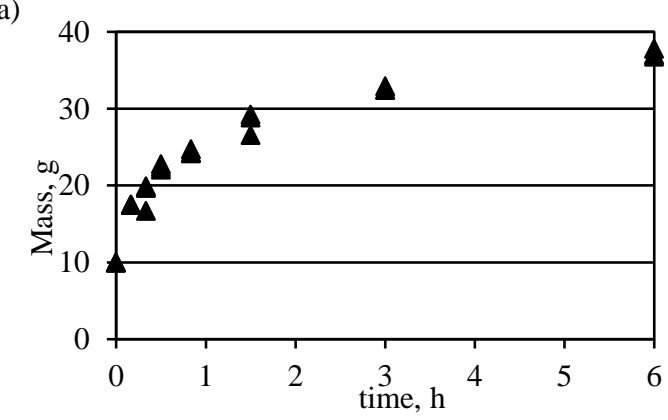

b)

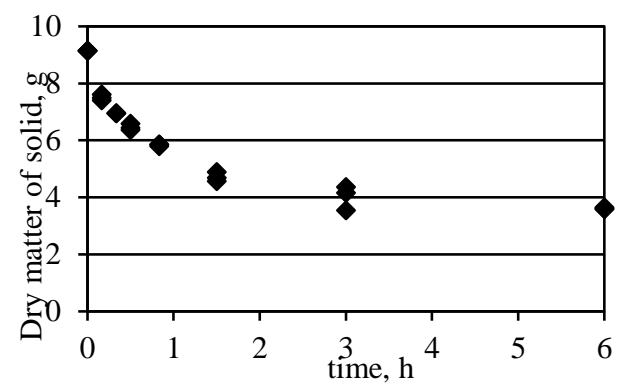

c)

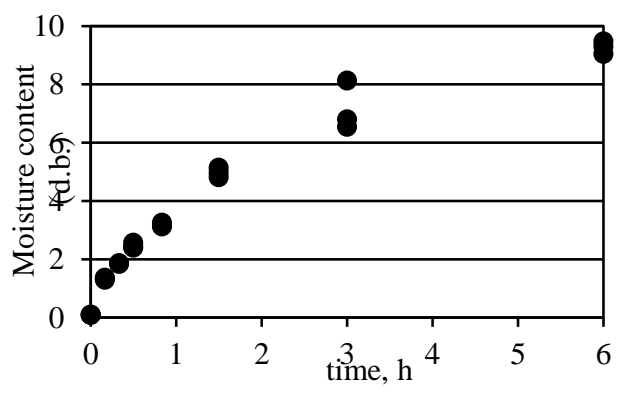

Figure. 1. Variation in a) mass, b) dry matter of solid, c) moisture content with time during rehydration of dried in natural convection at $60^{\circ} \mathrm{C}$ apple cubes $(10 \mathrm{~mm})$ immersed in distilled water at $20^{\circ} \mathrm{C}$

\begin{tabular}{|c|c|c|c|c|c|c|c|c|}
\hline \multirow{2}{*}{ No. } & \multirow{2}{*}{ Conditions of drying and rehydration } & \multicolumn{2}{|c|}{ Model parameters } & \multirow{2}{*}{$\mathrm{R}^{2}$} & \multirow{2}{*}{ MBE } & \multirow{2}{*}{ RMSE } & \multirow{2}{*}{$\chi^{2}$} & \multirow{2}{*}{ t-stat } \\
\hline & & $\alpha$ & $\beta$ & & & & & \\
\hline 1 & $t_{r}=20^{\circ} \mathrm{C}, t_{d}=60^{\circ} \mathrm{C}, 6 \mathrm{~m} / \mathrm{s}, 10 \mathrm{~mm}$ cube & 2.6556 & 0.7334 & 0.9775 & -0.0012 & 0.0412 & 0.0019 & 0.0294 \\
\hline 2 & $t_{r}=45^{\circ} \mathrm{C}, t_{d}=60^{\circ} \mathrm{C}, 6 \mathrm{~m} / \mathrm{s}, 10 \mathrm{~mm}$ cube & 2.2407 & 0.9783 & 0.9745 & 0.0038 & 0.0472 & 0.0026 & 0.0813 \\
\hline 3 & $t_{r}=70^{\circ} \mathrm{C}, t_{d}=60^{\circ} \mathrm{C}, 6 \mathrm{~m} / \mathrm{s}, 10 \mathrm{~mm}$ cube & 1.9664 & 0.8266 & 0.9935 & 0.0034 & 0.0247 & 0.0007 & 0.1379 \\
\hline 4 & $t_{r}=95^{\circ} \mathrm{C}, t_{d}=60^{\circ} \mathrm{C}, 6 \mathrm{~m} / \mathrm{s}, 10 \mathrm{~mm}$ cube & 0.7813 & 0.6433 & 0.9793 & 0.0034 & 0.0390 & 0.0017 & 0.0885 \\
\hline 5 & $t_{r}=20^{\circ} \mathrm{C}, t_{d}=60^{\circ} \mathrm{C}, 0.01 \mathrm{~m} / \mathrm{s}, 10 \mathrm{~mm}$ cube & 2.5198 & 0.8522 & 0.9899 & 0.0028 & 0.0285 & 0.0009 & 0.0975 \\
\hline 6 & $t_{r}=45^{\circ} \mathrm{C}, t_{d}=60^{\circ} \mathrm{C}, 0.01 \mathrm{~m} / \mathrm{s}, 10 \mathrm{~mm}$ cube & 2.1081 & 0.9301 & 0.9949 & 0.0005 & 0.0210 & 0.0005 & 0.0247 \\
\hline 7 & $t_{r}=70^{\circ} \mathrm{C}, t_{d}=60^{\circ} \mathrm{C}, 0.01 \mathrm{~m} / \mathrm{s}, 10 \mathrm{~mm}$ cube & 1.5503 & 0.7965 & 0.9930 & 0.0008 & 0.0247 & 0.0007 & 0.0317 \\
\hline 8 & $t_{r}=95^{\circ} \mathrm{C}, t_{d}=60^{\circ} \mathrm{C}, 0.01 \mathrm{~m} / \mathrm{s}, 10 \mathrm{~mm}$ cube & 0.8696 & 0.6847 & 0.9809 & 0.0092 & 0.0333 & 0.0013 & 0.2875 \\
\hline 9 & $t_{r}=20^{\circ} \mathrm{C}, t_{d}=60^{\circ} \mathrm{C}, 0.01 \mathrm{~m} / \mathrm{s}, 10 \mathrm{~mm}$ slice & 2.6203 & 1.0521 & 0.9506 & 0.0061 & 0.0696 & 0.0053 & 0.0882 \\
\hline 10 & $t_{r}=20^{\circ} \mathrm{C}, t_{d}=50^{\circ} \mathrm{C}, 0.5 \mathrm{~m} / \mathrm{s}, 10 \mathrm{~mm}$ slice & 2.6692 & 0.7747 & 0.9887 & 0.0040 & 0.0290 & 0.0009 & 0.1392 \\
\hline 11 & $t_{r}=20^{\circ} \mathrm{C}, t_{d}=60^{\circ} \mathrm{C}, 0.5 \mathrm{~m} / \mathrm{s}, 10 \mathrm{~mm}$ slice & 2.4258 & 0.7353 & 0.9951 & 0.0026 & 0.0197 & 0.0004 & 0.1323 \\
\hline 12 & $t_{r}=45^{\circ} \mathrm{C}, t_{d}=60^{\circ} \mathrm{C}, 0.5 \mathrm{~m} / \mathrm{s}, 10 \mathrm{~mm}$ slice & 1.8658 & 0.8522 & 0.9691 & -0.0008 & 0.0535 & 0.0034 & 0.0149 \\
\hline 13 & $t_{r}=70^{\circ} \mathrm{C}, t_{d}=60^{\circ} \mathrm{C}, 0.5 \mathrm{~m} / \mathrm{s}, 10 \mathrm{~mm}$ slice & 1.4147 & 0.7321 & 0.9957 & 0.0017 & 0.0189 & 0.0005 & 0.0921 \\
\hline 14 & $t_{r}=95^{\circ} \mathrm{C}, t_{d}=60^{\circ} \mathrm{C}, 0.5 \mathrm{~m} / \mathrm{s}, 10 \mathrm{~mm}$ slice & 0.6999 & 0.7176 & 0.9895 & 0.0032 & 0.0286 & 0.0010 & 0.1111 \\
\hline 15 & $t_{r}=20^{\circ} \mathrm{C}, t_{d}=70^{\circ} \mathrm{C}, 0.5 \mathrm{~m} / \mathrm{s}, 10 \mathrm{~mm}$ cube & 3.0272 & 0.7559 & 0.9901 & 0.0032 & 0.0259 & 0.0007 & 0.1244 \\
\hline 16 & $t_{r}=20^{\circ} \mathrm{C}, t_{d}=60^{\circ} \mathrm{C}, 0.5 \mathrm{~m} / \mathrm{s}, 3 \mathrm{~mm}$ slice & 1.7715 & 0.7205 & 0.9734 & -0.0045 & 0.0474 & 0.0025 & 0.0943 \\
\hline 17 & $t_{r}=20^{\circ} \mathrm{C}, t_{d}=60^{\circ} \mathrm{C}, 2 \mathrm{~m} / \mathrm{s}, 10 \mathrm{~mm}$ cube & 2.4364 & 0.7554 & 0.9934 & 0.0034 & 0.0226 & 0.0006 & 0.1510 \\
\hline 18 & $t_{r}=20^{\circ} \mathrm{C}, t_{d}=60^{\circ} \mathrm{C}, 2 \mathrm{~m} / \mathrm{s}, 10 \mathrm{~mm}$ slice & 2.9630 & 0.7507 & 0.9801 & 0.0017 & 0.0376 & 0.0016 & 0.0440 \\
\hline
\end{tabular}

Table 1. Results of statistical analyses on the modelling of dried apple rehydration using Weibull model

Figure 2 shows the relationship between the parameters $\alpha$ and $\beta$ calculated from experiment (their values are shown in Table 1) and predicted by using of Eqs. (4) and (5). The statistical analysis conducted on the Weibull model parameters 
$\alpha$ and $\beta$ gives the following results: generally high determination coefficient $R^{2}=0.9165$ (for $\alpha$ ) and 0.6694 (for $\beta$ ) and low values of $\mathrm{MBE}=0.0000$ and $0.0003, \quad \mathrm{RMSE}=0.1849$ and $0.0522, \quad \chi^{2}=0.0418$ and 0.0035 , and t-stat $=0.0000$ and 0.0064 respectively. Therefore, it can be accepted that considered Eqs. (4) and (5) may be used to represent parameters $\alpha$ and $\beta$ of the Weibull model.

a)

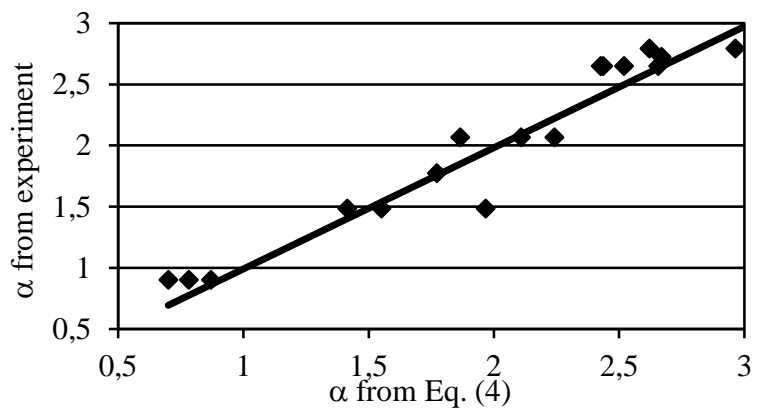

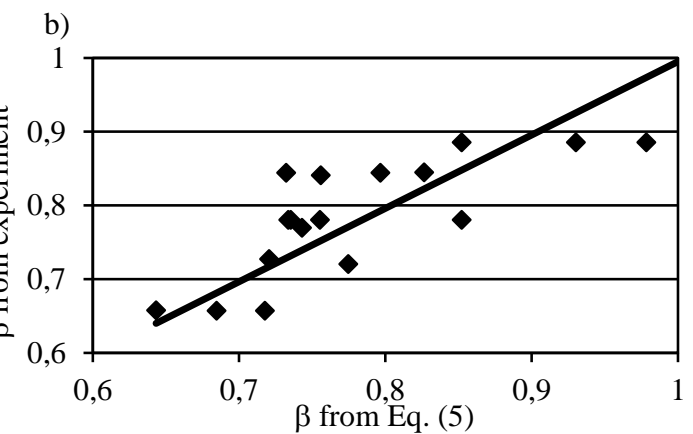

Figure 2. Parameters of the Weibull model calculated from experiment and predicted by using: a) Eq. (4) for scale parameter $\alpha, b)$ Eq. (5) for shape parameter $\beta$.

The Eqs. (4) and (5) were then used to estimate the moisture content of rehydrated dried apples at any time during rehydration. Validation of the developed extended Weibull model was made by comparing the computed moisture contents with the measured ones in any particular rehydrating run under certain conditions. The results of statistical analyses undertaken on the extended Weibull model are given in Table 2 . They are comparable with the results obtained for the Weibull model (Table 1).

Table 2. Results of statistical analyses on the modelling of dried apple rehydration using extended Weibull model

\begin{tabular}{|l|c|c|c|c|c|}
\hline No. & $\mathrm{R}^{2}$ & MBE & RMSE & $\chi^{2}$ & t-stat \\
\hline $\left.1^{*}\right)$ & 0.9768 & 0.0056 & 0.0430 & 0.0020 & 0.1306 \\
\hline 2 & 0.9686 & -0.0210 & 0.0562 & 0.0036 & 0.4009 \\
\hline 3 & 0.9913 & -0.0051 & 0.0330 & 0.0013 & 0.1555 \\
\hline 4 & 0.9807 & 0.0280 & 0.0477 & 0.0026 & 0.7265 \\
\hline 5 & 0.9886 & 0.0020 & 0.0323 & 0.0011 & 0.0618 \\
\hline 6 & 0.9940 & -0.0074 & 0.0230 & 0.0007 & 0.3424 \\
\hline 7 & 0.9927 & -0.0026 & 0.0267 & 0.0009 & 0.0976 \\
\hline 8 & 0.9814 & 0.0110 & 0.0317 & 0.0012 & 0.3702 \\
\hline 9 & 0.9486 & 0.0075 & 0.0720 & 0.0057 & 0.1042 \\
\hline 10 & 0.9870 & -0.0012 & 0.0317 & 0.0011 & 0.0389 \\
\hline 11 & 0.9948 & 0.0227 & 0.0294 & 0.0011 & 1.2214 \\
\hline 12 & 0.9666 & 0.0206 & 0.0578 & 0.0042 & 0.3805 \\
\hline 13 & 0.9913 & 0.0207 & 0.0311 & 0.0016 & 0.8958 \\
\hline 14 & 0.9912 & 0.0377 & 0.0513 & 0.0031 & 1.0801 \\
\hline 15 & 0.9882 & -0.0118 & 0.0391 & 0.0017 & 0.3157 \\
\hline 16 & 0.9734 & -0.0037 & 0.0474 & 0.0025 & 0.0778 \\
\hline 17 & 0.9942 & 0.0211 & 0.0298 & 0.0010 & 1.0014 \\
\hline 18 & 0.9797 & -0.0047 & 0.0389 & 0.0017 & 0.1210 \\
\hline
\end{tabular}

The values of $\mathrm{R}^{2}$ are high (0.9130-0.9948) and the values of MBE (-0.0209-0.0377), RMSE (0.0230-0.0719), $\chi^{2}$ (0.0007-0.0057), and t-stat (0.0389-1.2214) are quite low.

Figure 3 shows the relationship between the moisture ratio calculated experimentally (Eq. 2) and the moisture ratio calculated by using the extended Weibull model (Eqs. (3), (4), and (5)). As shown in Fig. 3 it can be accepted that the extended Weibull model provided a good fit to moisture ratio calculated experimental data for rehydration of dried apples $\left(\mathrm{R}^{2}=0.9776, \mathrm{MBE}=0.0081, \mathrm{RMSE}=0.0620, \chi^{2}=0.0040\right.$, and $\left.\mathrm{t}-\mathrm{stat}=0.3477\right)$.

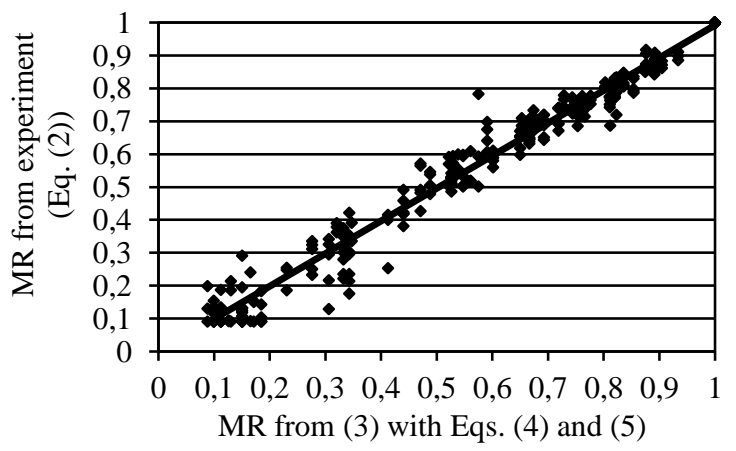

Figure 3. Experimentally determined and predicted from the extended Weibull model moisture content of rehydrated dried apples 
This shows the suitability of the extended Weibull model for explaining the kinetics of rehydration of dried apples. Although both Weibull and extended Weibull model are empirical ones, the extended model by taking into account the effect of process conditions $\left(L, v, t_{d}, t_{r}\right)$ on model parameters can be considered as more general.

\section{CONCLUSIONS}

1. Moisture uptake and solute loss increases with increasing rehydration time, and the rate is faster in the initial period of rehydration and decreased up to the saturation level.

2. The Weibull model can be considered as the appropriate for describing the rehydration of dried apple $\left(\mathrm{R}^{2} \in(0.8319\right.$ 0.9957), MBE $\left.\in(-0.0044-0.0108), \operatorname{RMSE} \in(0.0189-0.1248), \chi^{2} \in(0.0004-0.0180), \mathrm{t}-\mathrm{stat} \in(0.0149-0.2875)\right)$.

3. Developed empirical formulas can be considered as appropriate for describing the Weibull model constants $\alpha$ $\left(\mathrm{R}^{2}=0.9165, \mathrm{MBE}=0.0000, \mathrm{RMSE}=0.1849, \chi^{2}=0.0418, \mathrm{t}-\mathrm{stat}=0.0000\right)$ and $\beta\left(\mathrm{R}^{2}=0.6694, \mathrm{MBE}=0.0003, \mathrm{RMSE}=\right.$ $0.0522, \chi^{2}=0.0035, \mathrm{t}$-stat $\left.=0.0064\right)$

4. The extended Weibull model can be considered as the appropriate for describing the rehydration of dried apple $\left(\mathrm{R}^{2}=0.9776, \mathrm{MBE}=0.0081, \mathrm{RMSE}=0.0620, \chi^{2}=0.0040, \mathrm{t}\right.$-stat=0.3477).

5. The developed extended Weibull model by taking into account the effect of characteristic particle dimension, drying air velocity, drying air temperature, and rehydration temperature on model parameters can be considered as more general one.

\section{Acknowledgements}

The authors are grateful for the financial support from research project N N313 780940 from the National Science Centre, Poland.

\section{REFERENCES}

1. AOAC 2003. Official Methods of Analysis. Association of official Analytical Chemists No 934.06, Arlington VA.

2. Cunningham S. E., McMill W. A. M., Magee T. R. A., Richardson P. S. 2008. Effect of Processing Conditions on the Water Absorption and Texture Kinetics of Potato. Journal of Food Engineering, Vol. 84, No. 2, pp. $214-223$. https://doi.org/10.1016/j.jfoodeng.2007.05.007

3. Ergün, K., Çalişkan, G., Dirim, S. N. 2016. Determination of the Drying and Rehydration Kinetics of Freeze Dried Kiwi (Actinidia Deliciosa) slices. Heat Mass Transfer, Vol. 52, pp.2697-2705. https://doi.org/10.1007/s00231-016-1773-x

4. Garcia-Pascual, P., Sanjuán, N., Bon, J., Carreres, J. E., Mulet, A. 2005. Rehydration Process of Boletus Edulis Mushroom: Characteristics and Modelling. Journal of the Science of Food and Agriculture, Vol. 85, pp. $1397-1404$. https://doi.org/10.1002/jsfa.2126

5. Garcia-Pascual, P., Sanjuán, N., Melis, R., Mulet, A. 2006. Morchella Esculenta (morel) Rehydration Process Modelling. Journal of Food Engineering, Vol. 72, pp. 346-353. https://doi.org/10.1016/j.jfoodeng.2004.12.014

6. Górnicki, K. 2011. Modelling of Selected Vegetables and Fruits Rehydration Process, Wyd. SGGW, Warsaw.

7. Link, J. V., Tribuzi, G., Laurindo, J. B. 2017. Improving Quality of Dried Fruits: A Comparison between Conductive Multi-Flash and Traditional Drying Methods. LWT - Food Science and Technology, Vol. 84, pp. $717-725$. https://doi.org/10.1016/j.lwt.2017.06.045

8. Machado, M. F., Oliveira, F. A. R., Cunha, L. M. 1999. Effect of Milk Fat and Total Solids Concentrations on the Kinetics of Moisture Uptake by Ready-to-Eat Breakfast Cereal. International Journal of Food Science and Technology, Vol. 34, pp. 47-57. https://doi.org/10.1046/j.1365-2621.1999.00238.x

9. Maldonado, S., Arnau, E., Bertuzzi, M. A. 2010. Effect of Temperature and Pretreatment on Water Diffusion during Rehydration of Dehydrated Mangoes. Journal of Food Engineering, Vol. 96, pp. 333-341. https://doi.org/10.1016/j.jfoodeng.2009.08.017

10. Markowski, M., Bondaruk, J., Błaszczak, W. 2009. Rehydration Behavior of Vacuum-Microwave-Dried Potato Cubes. Drying Technology, Vol. 27, pp. 296-305. https://doi.org/10.1080/07373930802606600

11. Pabis, S., Jayas, D. S., Cenkowski, S. 1998. Grain Drying. Theory and Practice, John Wiley \& Son Inc., New York.

12. Peleg, M. 1988. An Empirical Model for the Description of Moisture Sorption Curves. Journal of Food Science, Vol. 53, pp. 1216--1219. https://doi.org/10.1111/j.1365-2621.1988.tb13565.x

13. Rafiq, A., Chawdhary, J., Hazarika, M. K., Makroo, H. A. 2015. Temperature Dependence on Hydration Kinetic Model Parameters during Rehydration of Parboiled Rice. Journal of Food Science and Technology, Vol. 52, pp. 6090-6094. https://doi.org/10.1007/s13197-015-1790-7

14. Saguy, I. S., Marabi, A., Wallach, R. 2005. New approach to model rehydration of dry food particulates utilizing principles of liquid transport in porous media. Trends in Food Science and Technology, Vol. 16, pp. $495-506$. https://doi.org/10.1016/j.tifs.2005.07.006

15. Sopade, P. A., Xun, P. Y., Halley, P. J., Hardin M. 2007. Equivalence of the Peleg, Pilosof and Singh-Kulshrestha Models for Water Absorption in Food. Journal of Food Engineering, Vol. 78, Iss. 2, pp. $730-734$. ttps://doi.org/10.1016/j.jfoodeng.2005.10.007

16. Witrowa-Rajchert, D. 1999. Rehydration as an Index of Changes Occurring in Plant Tissue during Drying, Fundacja "Rozwój SGGW", Warsaw. 